\title{
Occult renal dysfunction: a mortality and morbidity risk factor in coronary artery bypass grafting surgery
}

\author{
Antonio Miceli, MD, ${ }^{\mathrm{a}, \mathrm{b}}$ Vito D. Bruno, MD, ${ }^{\mathrm{a}}$ Radek Capoun, MD, ${ }^{\mathrm{a}}$ Francesco Romeo, MD, \\ Gianni D. Angelini, FRCS, ${ }^{\mathrm{a}}$ and Massimo Caputo, $\mathrm{MD}^{\mathrm{a}}$
}

\begin{abstract}
Objective: Elevated preoperative serum creatinine is considered an independent risk factor for postoperative mortality and morbidity in patients undergoing coronary artery bypass grafting. However, the impact of occult renal dysfunction, defined as an impairment of glomerular filtration rate with normal serum creatinine, is still unknown. The aim of this study was to analyze the effects of occult renal dysfunction on early outcomes after coronary artery bypass grafting.
\end{abstract}

\begin{abstract}
Methods: This was a retrospective, observational, cohort study of prospectively collected data on 9159 consecutive patients with normal serum creatinine levels undergoing coronary artery bypass grafting between April 1996 and February 2009. Patients were divided into two groups based on preoperative creatinine clearance estimated with the Cockcroft-Gault equation: 5484 patients with a creatinine clearance $\geq 60 \mathrm{~mL} / \mathrm{min}$ and 3675 patients with a creatinine clearance $<60 \mathrm{~mL} / \mathrm{min}$ (occult renal dysfunction group).

Results: Overall in-hospital mortality was $1 \%$. Occult renal dysfunction was associated with a doubling in the risk of operative mortality $(1.4 \%$ vs $0.7 \% ; P=.001)$, postoperative renal dysfunction $(5.1 \%$ vs $2.5 \%$; $P<.0001)$, and need for dialysis $(0.8 \%$ vs $0.4 \% ; P=.014)$. Moreover, occult renal dysfunction increased the risk of stroke $(1 \%$ vs $0.3 \% ; P<.0001)$, arrhythmia $(28.5 \%$ vs $21.2 \% ; P<.0001)$, and hospital stay $>7$ days (36.45 vs $24.5 \% ; P<.0001)$. In a multivariable analysis adjusting for preoperative risk factors, occult renal dysfunction was confirmed to be an independent predictor of mortality (odds ratio, 1.72), postoperative renal dysfunction (odds ratio, 1.9), dialysis (odds ratio, 1.82), stroke (odds ratio, 2.6) arrhythmia (odds ratio, 1.42), and hospital stay $>7$ days (odds ratio, 1.65).
\end{abstract}

Conclusions: Occult renal dysfunction is an independent risk factor for early mortality and morbidity in patients undergoing coronary artery bypass grafting. (J Thorac Cardiovasc Surg 2011;141:771-6)

Elevated preoperative serum creatinine ( $\mathrm{SCr}$ ) is considered an independent risk factor for postoperative mortality and morbidity in patients undergoing cardiac surgery. ${ }^{1-4}$ The overall mortality risk for patients with preoperative $\mathrm{SCr}>130 \mu \mathrm{mol} / \mathrm{L}(1.5 \mathrm{mg} / \mathrm{dL})$ ranges from $5 \%$ to $30 \%$ and the probability of death increases with the increasing preoperative $\mathrm{SCr}$ level. ${ }^{2-6}$

Serum creatinine is a specific marker of renal dysfunction; however, because its generation is determined by age, race, muscle mass, and dietary intake other than filtration creatinine, it can remain within the normal range when renal function is significantly impaired. ${ }^{7,8}$

\footnotetext{
From the Bristol Heart Institute, ${ }^{\text {a }}$ University of Bristol, Bristol, United Kingdom; and University of Tor Vergata, ${ }^{b}$ Rome, Italy.

Supported by The British Heart Foundation, the Garfield Weston Trust, and the NIHR Bristol Biomedical Research Unit in Cardiovascular Medicine.

Disclosures: Authors have nothing to disclose with regard to commercial support.

Received for publication April 25, 2010; revisions received July 23, 2010; accepted for publication Aug 1, 2010; available ahead of print Sept 30, 2010.

Address for reprints: Gianni D. Angelini, FRCS, Bristol Heart Institute, Bristol BS2 8HW, United Kingdom (E-mail: G.D.Angelini@bris.ac.uk).

$0022-5223 / \$ 36.00$

Copyright (c) 2011 by The American Association for Thoracic Surgery

doi:10.1016/j.jtcvs.2010.08.016
}

Estimated creatinine clearance $(\mathrm{eCrCl})$ has been described as a more sensitive screening test in predicting renal reserve and a better predictor of mortality and morbidity than SCr in cardiac surgery. ${ }^{5,9-11}$ On the contrary, Cooper and colleagues ${ }^{12}$ analyzed 483,914 patients undergoing coronary artery bypass grafting $(\mathrm{CABG})$ and suggested that various measures of renal function, including $\mathrm{SCr}$, performed similarly well in models predicting operative mortality. However, in all these studies, limited information is given on the risk associated with occult renal dysfunction (ORD).

The National Kidney Foundation defined chronic kidney disease as glomerular filtration rate (GFR) $<60 \mathrm{~mL} / \mathrm{min} /$ $1.73 \mathrm{~m}^{2}$ for $\geq 3$ months, with or without kidney damage, and that GFR may be derived by eCrCl. ${ }^{13}$ According to this definition, the prevalence of chronic renal disease is among 63 million people in the United States, and it is associated with increased risk of cardiovascular events. ${ }^{13,14}$ Given the rising incidence and prevalence of cardiovascular disease with declining renal function, it is important to understand the impact of ORD on adverse events in patients undergoing cardiac surgery. ${ }^{14,15}$ Therefore, the aim of our study was to evaluate the effect of ORD, defined as an impairment of glomerular filtration rate with normal $\mathrm{SCr}$, on early clinical outcomes in patients undergoing CABG. 


$$
\begin{aligned}
& \text { Abbreviations and Acronyms } \\
& \begin{aligned}
\mathrm{CABG} & =\text { coronary artery bypass grafting } \\
\mathrm{CI} & =\text { confidence interval } \\
\mathrm{CrCl} & =\text { creatinine clearance } \\
\mathrm{eCrCl} & =\text { estimated creatinine clearance } \\
\mathrm{GFR} & =\text { glomerular filtration rate } \\
\mathrm{ORD} & =\text { occult renal dysfunction } \\
\mathrm{MI} & =\text { myocardial infarction } \\
\mathrm{OR} & =\text { odds ratio } \\
\mathrm{PRD} & =\text { postoperative renal dysfunction } \\
\mathrm{SCr} & =\text { serum creatinine }
\end{aligned}
\end{aligned}
$$

\section{MATERIALS AND METHODS \\ Patient Selection and Data Definitions}

This was a retrospective, observational, cohort study of prospectively collected data from consecutive patients undergoing CABG at the Bristol Heart Institute between April 1996 and February 2009. The study was approved by the clinical audit committee of the University Hospital Bristol National Health Service Foundation Trust to meet ethical and legal requirements and individual consent was waived. The data collection form is entered in a database (Patient Analysis \& Tracking System; Dendrite Clinical Systems, London, UK) and includes 5 sections that are filled in consecutively by anesthetists, surgeons, and intensive care unit, high dependency unit, and ward nurses.

The normal range for $\mathrm{SCr}$ was defined as 30 to $130 \mu \mathrm{mol} / \mathrm{L}(0.34-1.47$ $\mathrm{mg} / \mathrm{dL}$ ) and these limits represent the 97.5 percentile of the distribution of SCr levels in healthy male and female volunteers. ${ }^{8}$ We analyzed data on all of the patients undergoing isolated CABG with a preoperative $\mathrm{SCr} \leq 130$ $\mu \mathrm{mol} / \mathrm{L}(\leq 1.47 \mathrm{mg} / \mathrm{dL})$. Exclusion criteria were patients who had unknown SCr concentration before surgery (210 patients) and $\mathrm{SCr}>130$ $\mu \mathrm{mol} / \mathrm{L}$ ( $>1.47 \mathrm{mg} / \mathrm{dL} ; 1480$ patients). According to the National Kidney Foundation, ${ }^{13}$ preoperative renal dysfunction was defined as GFR $<60 \mathrm{mg} /$ $\mathrm{mL} / 1.73 \mathrm{~m}^{2}$, and measurement of GFR was estimated on the basis of the Cockroft and Gault ${ }^{16}$ equation as follows:

$$
\mathrm{eCrCl}=\frac{(140-A g e) \times \text { Weight }[\mathrm{kg}](\times 0.85 \text { if woman })}{72 \times(\operatorname{Scr}[\mu \mathrm{mol} / \mathrm{L}] / 88.4)}
$$

in which 88.4 is a conversion factor to express $\mathrm{SCr}$ in $\mathrm{mg} / \mathrm{dL}$.

The final sample size was made of 9159 patients who were divided into two groups based on eCrCl level: 5484 patients with an $\mathrm{eCrCl} \geq 60 \mathrm{~mL} /$ min (control patients group) and $3675(40.1 \%)$ patients with $\mathrm{eCrCl}<60$ $\mathrm{mL} / \mathrm{min}$ (ORD group). Baseline characteristics were defined according to EuroSCORE model. ${ }^{1}$ The decision to perform off-pump or on-pump CABG technique was based on individual surgeon preference.

\section{Study End Points}

The primary end point was in-hospital mortality, defined as any death occurring within 30 days of operation. Secondary end points were postoperative renal dysfunction (PRD), need for postoperative dialysis/hemofiltration, arrhythmia, myocardial infarction (MI), stroke, and hospital stay $>7$ days. A diagnosis of postoperative MI was based on the presence of Q waves $>$ $0.04 \mathrm{~ms}$, and/or a reduction in $\mathrm{R}$ waves $>25 \%$ in at least two contiguous leads on echocardiogram. The PRD was defined as SCr level $>200 \mu \mathrm{mol} / \mathrm{L}$, plus an increase of at least 1.5 times preoperative baseline concentrations. Postoperative arrhythmia was defined as any presence of supraventricular arrhythmia. A diagnosis of stroke was made if there was evidence of new neurologic deficit with morphologic substrate confirmed by computer tomography or nuclear magnetic resonance imaging.

\section{Anesthetic, Surgical Technique, and Postoperative Management}

Anesthetic and surgical techniques were standardized for all patients and have been reported previously. ${ }^{17,18}$ In brief, for patients undergoing on-pump CABG, cardiopulmonary bypass was instituted with the use of ascending aortic cannulation and two-stage venous cannulation of the right atrium. The membrane oxygenator was primed with $1000 \mathrm{~mL}$ of Hartmann's crystalloid, $500 \mathrm{~mL}$ Gelofusine (B Braun Medical Ltd, Emmenbrucke, Switzerland), $0.5 \mathrm{~g} / \mathrm{kg}$ mannitol, $7 \mathrm{~mL}$ of $10 \%$ calcium gluconate, and $6000 \mathrm{IU}$ heparin. Alpha-stat $\mathrm{pH}$ management was used, and the systemic temperature was kept between $34^{\circ} \mathrm{C}$ and $36^{\circ} \mathrm{C}$. Myocardial protection was achieved with intermittent hyperkalaemic warm blood cardioplegia. For off-pump CABG, the Bristol technique was used to expose the coronaries and provide stabilization to undertake the anastomosis. ${ }^{18}$ At the end of surgery, patients were transferred to the intensive care unit and managed according to the unit protocol. ${ }^{17,18}$

\section{Statistical Analysis}

Continuous data were expressed as mean \pm standard deviation, and categorical data as percentages. The Kolmogorov-Smirnov test was used to check for normality of data in the two groups before further analysis. Differences between ORD and control group were compared using $\chi^{2}$ test for categorical variables, and the Student $t$ test or the Wilcoxon rank sum test, as appropriate, for continuous variables. To reduce the effect of selection bias and potential confounding in this observational study, a propensity score was undertaken. ${ }^{19}$ The propensity for ORD was determined without regard of outcomes by the use of a nonparsimoious multiple logisticregression analysis. All the variables listed in Table 1 were included in the analysis. Logistic regression was performed to assess the effect associated with ORD on each end point after adjusting for potentially confounding variables listed in Table 1 and the propensity score. Results are reported as percentages and odds ratios (OR) with $95 \%$ confidence interval (CI). All reported $P$ values are two-sided, and $P$ values of less than .05 were considered to indicate statistical significance. All statistical analysis was performed with SPSS 15.0 (SPSS Inc, Chicago, Ill).

\section{RESULTS}

In the study population of 9159 patients with normal $\mathrm{SCr}$ levels, a total of $3675(40.1 \%)$ patients had an $\mathrm{eCrCl}<60$ $\mathrm{mL} / \mathrm{min}$ and were classified as having ORD (Figure 1). The mean ( \pm standard deviation) eCrCl was $51.4(5.8) \mathrm{mL} / \mathrm{min}$ versus $73.3(11.2) \mathrm{mL} / \mathrm{min}$, in the ORD and control patients group, respectively. Baseline characteristics of the study population are shown in Table 1 . Patients in the ORD group were older and more often female; they were more likely to have a lower angina functional class, greater prevalence of hypertension, chronic obstructive pulmonary disease, extracardiac arteriopathy, and previous cardiac operations. Patients with ORD were also more likely to have a lower ejection fraction and greater prevalence of New York Heart Association functional class. The prevalence of the off-pump procedure was similar between the two groups.

The overall rate of mortality was $1 \%$. Results from univariate and multivariable logistic analysis are reported in Tables 2 and 3. The ORD was associated with a doubling in the risk of death (53 patients [1.4\%] vs 38 patients [0.7\%]; OR, 2.1; 95\% CI, 1.38-3.19; $P=.001)$, PRD (189 patients [5.1\%] vs 138 patients [2.5\%]; OR, 2.1; 
TABLE 1. Baseline characteristics of the patients

\begin{tabular}{|c|c|c|c|}
\hline Variables & $\mathrm{CrCl}<60 \mathrm{~mL} / \mathrm{min}(\mathrm{n}=3675)$ & $\mathrm{CrCl}>60 \mathrm{~mL} / \mathrm{min}(\mathrm{n}=5484)$ & $P$ value \\
\hline Age, mean $\pm \mathrm{SD}(\mathrm{y})$ & $70.7 \pm 6$ & $59.6 \pm 8.3$ & $<.0001$ \\
\hline Female & $1045(28.4)$ & $742(13.5)$ & $<.0001$ \\
\hline $\mathrm{eCrCl}$, mean $\pm \mathrm{SD}(\mathrm{mL} / \mathrm{min})$ & $51.4 \pm 5.8$ & $73.3 \pm 11.2$ & $<.0001$ \\
\hline CCS 3-4 class & $2028(55.2)$ & $2675(48.8)$ & $<.0001$ \\
\hline NYHA III-IV class & $1208(32.9)$ & $1506(27.5)$ & $<.0001$ \\
\hline Diabetes & $523(14.2)$ & $825(15)$ & .296 \\
\hline Hypertension & $2525(68.4)$ & $3443(62.8)$ & $<.0001$ \\
\hline COPD & $407(11.1)$ & $519(9.5)$ & .013 \\
\hline Neurologic disease & $47(1.3)$ & $56(1)$ & .296 \\
\hline Extracardiac arteriopaty & $365(9.9)$ & $398(7.3)$ & $<.0001$ \\
\hline Previous cardiac surgery & $118(3.2)$ & $121(2.2)$ & .004 \\
\hline Critical preoperative state & $62(1.7)$ & $65(1.2)$ & .055 \\
\hline Preoperative EF & & & $<.0001$ \\
\hline Good & $2658(72.3)$ & $4234(77.2)$ & \\
\hline Fair & $845(23)$ & $1058(19.3)$ & \\
\hline Poor & $172(4.7)$ & $192(3.5)$ & \\
\hline Recent MI & $1302(35.4)$ & $1843(33.6)$ & .076 \\
\hline Emergency & $71(1.9)$ & $96(1.8)$ & .578 \\
\hline No. grafts performed & $2.74 \pm 0.79$ & $2.68 \pm 0.84$ & .001 \\
\hline Off-pump surgery & $1720(46.9)$ & $2263(48.7)$ & .103 \\
\hline
\end{tabular}

Value are express as $\mathrm{n}=$ number of patients and (\%) unless specified. $C C S$, Canadian Cardiovascular Society; $C O P D$, chronic obstructive pulmonary disease; $e C r C l$, estimated creatinine clearance; $E F$, ejection fraction; NYHA, New York Heart Association; $M I$, myocardial infarction; $S D$, standard deviation.

$95 \%$ CI, $1.68-2.27 ; P<.0001)$, and need for dialysis $(30$ patients $[0.8 \%]$ vs 22 patients $[0.4 \%]$; OR, $2 ; 95 \% \mathrm{CI}$, $1.18-3.58 ; P=.014)$. There was a significant difference between ORD and the control patients group in the risk of stroke (35 patients [1\%] vs 18 patients [0.3\%]; OR, 2.9; 95\% CI, 1.65-5.16; $P<.0001$ ), arrhythmia (1046 patients [28.5\%] vs 1163 patients [21.2\%]; OR, $1.48 ; 95 \%$ CI, $1.34-1.63 ; P<.0001$ ), and hospital stay $>7$ days. After adjusting for confounding variables listed in Table 1 , as well as propensity score, the ORD remained an important predictor of mortality (OR, 1.72; 95\% CI, 1.12-2.64; C-statistic, 0.78), PRD (OR, 1.9; 95\% CI, 1.53-2.41; C statistic, 0.84 ), need for dialysis (OR, 1.82; 95\% CI,1.01-3.2; C-statistic, 0.77), stroke (OR, 2.6; $95 \% \mathrm{CI}, 1.47-4.67$; C statistic, 0.8 ), arrhythmia (OR, 1.42; 95\% CI, 1.28-1.57; C statistic, $0.81)$. The ORD was not significantly associated with increased risk of postoperative MI in either univariate or multivariable analysis. The median length of hospital stay was 6 days (interquartile range, 5 to 8 ). The rate of hospital stay $>7$ days was higher in the ORD group (1337 patients [36.4\%] vs 1344 patients [24.5\%]; OR, $1.76 ; 95 \% \mathrm{CI}$, $1.61-1.93 ; P<.0001)$ and at multivariable analysis, the ORD group was confirmed to be a predictor of length of stay $>7$ days (OR, $1.65 ; 95 \%$ CI, 1.5-1.81; C statistic, 0.82 ). When modeled as univariate continuous variable, a curvilinear relationship was seen between the estimated probability of death and $\mathrm{eCrCl}$; a similar relationship was observed between $\mathrm{eCrCl}$ and the estimated probability of PRD (Figure 2).

\section{DISCUSSION}

Our study demonstrates that ORD, defined as an impairment of glomerular filtration rate $(\mathrm{eCrCl}<60 \mathrm{~mL} / \mathrm{min})$ with normal $\mathrm{SCr}$ level, is a mortality and morbidity risk factor in patients undergoing CABG. Specifically, we found that ORD was associated with doubling in the risk of death, PRD, and dialysis. Moreover, ORD increased the risk of stroke, arrhythmia, and length of hospital stay $>7$ days. We observed no significant relationship between ORD and the risk of postoperative MI.

Earlier studies, as well as the most common risk stratifications, rely on $\mathrm{SCr}$ as a screening test for estimating renal reserve in predicting adverse outcomes in cardiac surgery. ${ }^{1,20-22}$ The accuracy of $\mathrm{SCr}$ as indicator of renal disease is limited because it depends on several nonrenal factors, as well as filtration creatinine; therefore $\mathrm{SCr}$ levels may remain within the normal range when renal function is significantly impaired. The National Kidney Foundation published clinical guidelines on evaluation, classification, and risk stratification in chronic renal failure, identifying the GFR as the best measure of overall kidney function. ${ }^{13}$ Chronic kidney disease was defined as GFR $<60 \mathrm{~mL} / \mathrm{min} /$ $1.73 \mathrm{~m}^{2}$ for more than 3 months with or without kidney damage. This cutoff represents loss of half or more of the adult level of normal kidney function. ${ }^{13}$ However, because practical limitations exist in measuring GFR directly, eCrCl was considered as an alternative measure of renal function that estimates GFR. ${ }^{7,13,16}$ An increased risk of postoperative mortality and morbidity with decreased estimated GFR 


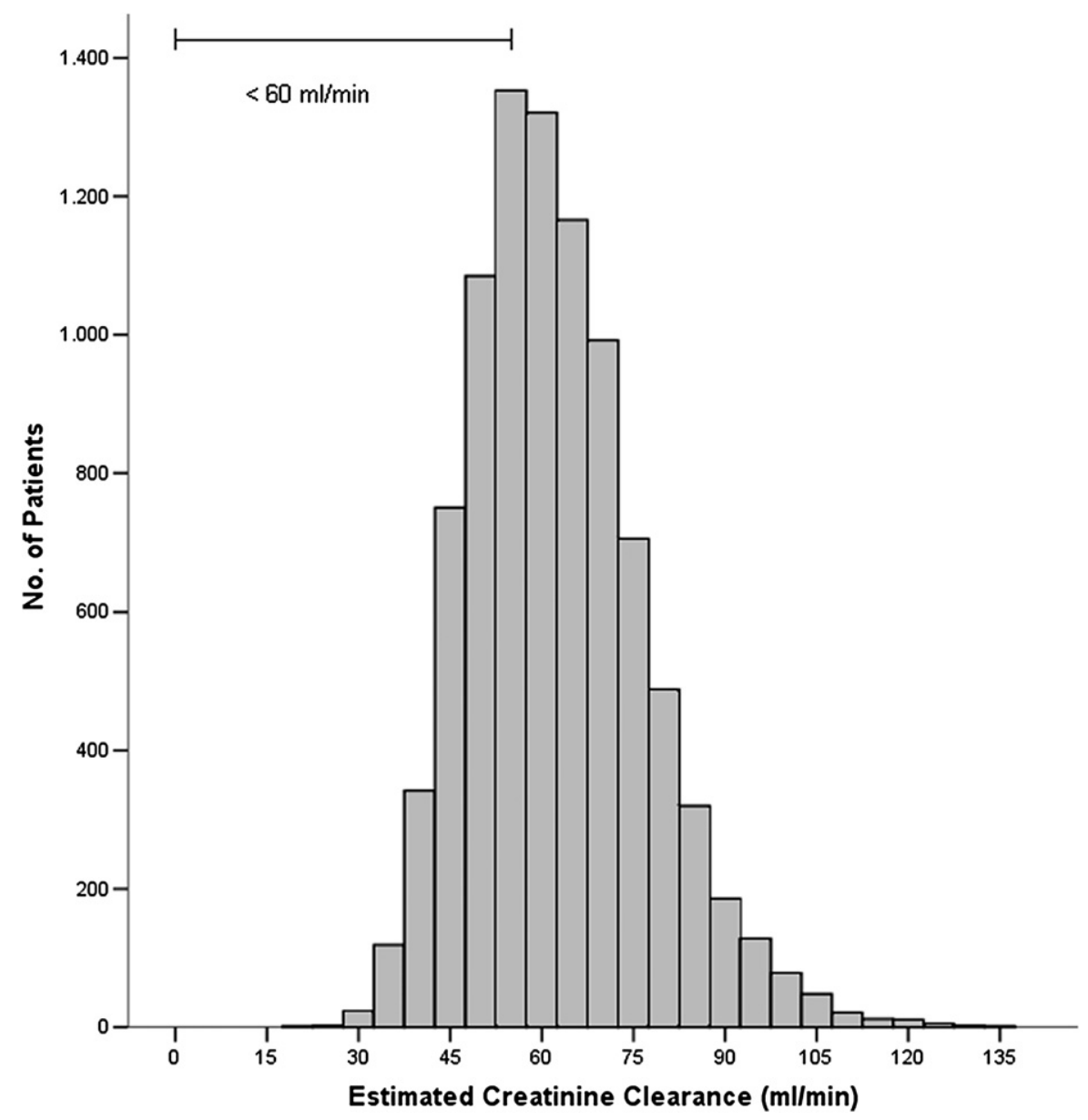

FIGURE 1. Distribution of estimated creatinine clearance among patients in the study.

has been previously described among patients undergoing cardiac surgery. ${ }^{9-12}$ However, only sub-analysis of a few studies have focused on patients with normal range $\mathrm{SCr}$ levels and reduced renal function. ${ }^{5,11}$ Wang and colleagues ${ }^{5}$ revealed that among 4603 patients with normal plasma creatinine levels undergoing cardiac surgery, $28 \%$ had an estimated $\mathrm{CrCl}<60 \mathrm{~mL} / \mathrm{min}$ that was associated with increased risk of mortality, renal failure requiring dialysis, and major morbidity including cardiovascular, respira-

TABLE 2. Clinical outcomes

\begin{tabular}{lccc}
\hline \multicolumn{1}{c}{ Outcomes } & $\begin{array}{c}\text { CrCl }<\text { 60 } \mathbf{~ m L} / \mathbf{m i n} \\
(\mathbf{n}=\mathbf{3 6 7 5})\end{array}$ & $\begin{array}{c}\mathbf{C r C l}>\mathbf{6 0} \mathbf{~ m L} / \mathbf{m i n} \\
(\mathbf{n}=\mathbf{5 4 8 4})\end{array}$ & $\begin{array}{c}\boldsymbol{P} \\
\text { value }\end{array}$ \\
\hline Mortality & $53(1.4)$ & $38(0.7)$ & .001 \\
Renal dysfunction & $189(5.1)$ & $138(2.5)$ & $<.0001$ \\
Dialysis & $30(0.8)$ & $22(0.4)$ & .014 \\
MI & $99(2.7)$ & $129(2.4)$ & .337 \\
Stroke, n (\%) & $35(1)$ & $18(0.3)$ & $<.0001$ \\
Arrhythmia, n (\%) & $1046(28.5)$ & $1163(21.2)$ & $<.0001$ \\
Hospital stay & $1337(36.4)$ & $1344(24.5)$ & $<.0001$ \\
$\quad>7$ days, n (\%) & & & \\
\hline
\end{tabular}

Results are expressed as $\mathrm{n}=$ number of patients and (\%). $\mathrm{CrCl}$, Creatinine clearance; $M I$, myocardial infarction. tory, neurologic, and infectious events. ${ }^{5}$ In Wijeysundera and colleagues, ${ }^{11} 13 \%$ of individual with normal $\mathrm{SCr}$ were found to have ORD; in comparison with patients with normal renal function, patients with ORD experienced more than 3-fold increased risk of mortality and renal replacement therapy. ${ }^{11}$ Both these studies were focused on

TABLE 3. Observed and adjusted ORs of postoperative adverse outcomes after CABG, according to presence or absence of occult renal dysfunction

\begin{tabular}{|c|c|c|}
\hline \multirow[b]{2}{*}{ Outcomes } & \multicolumn{2}{|c|}{ OR } \\
\hline & Crude $(95 \%$ CI $)$ & Adjusted* $(95 \%$ CI $)$ \\
\hline Mortality & $2.1(1.38-3.19)$ & $1.72(1.12-2.64)$ \\
\hline Renal dysfunction & $2.1(1.68-2.27)$ & $1.9(1.53-2.41)$ \\
\hline Dialysis & $2(1.18-3.58)$ & $1.82(1.01-3.2)$ \\
\hline MI & $1.15(0.88-1.5)$ & $1.1(0.84-1.44)$ \\
\hline Stroke & $2.9(1.65-5.16)$ & $2.6(1.47-4.67)$ \\
\hline Arrhythmia & $1.48(1.34-1.63)$ & $1.42(1.28-1.57)$ \\
\hline $\begin{array}{r}\text { Hospital stay } \\
(>7 \text { days })\end{array}$ & $1.76(1.61-1.93)$ & $1.65(1.5-1.81)$ \\
\hline
\end{tabular}




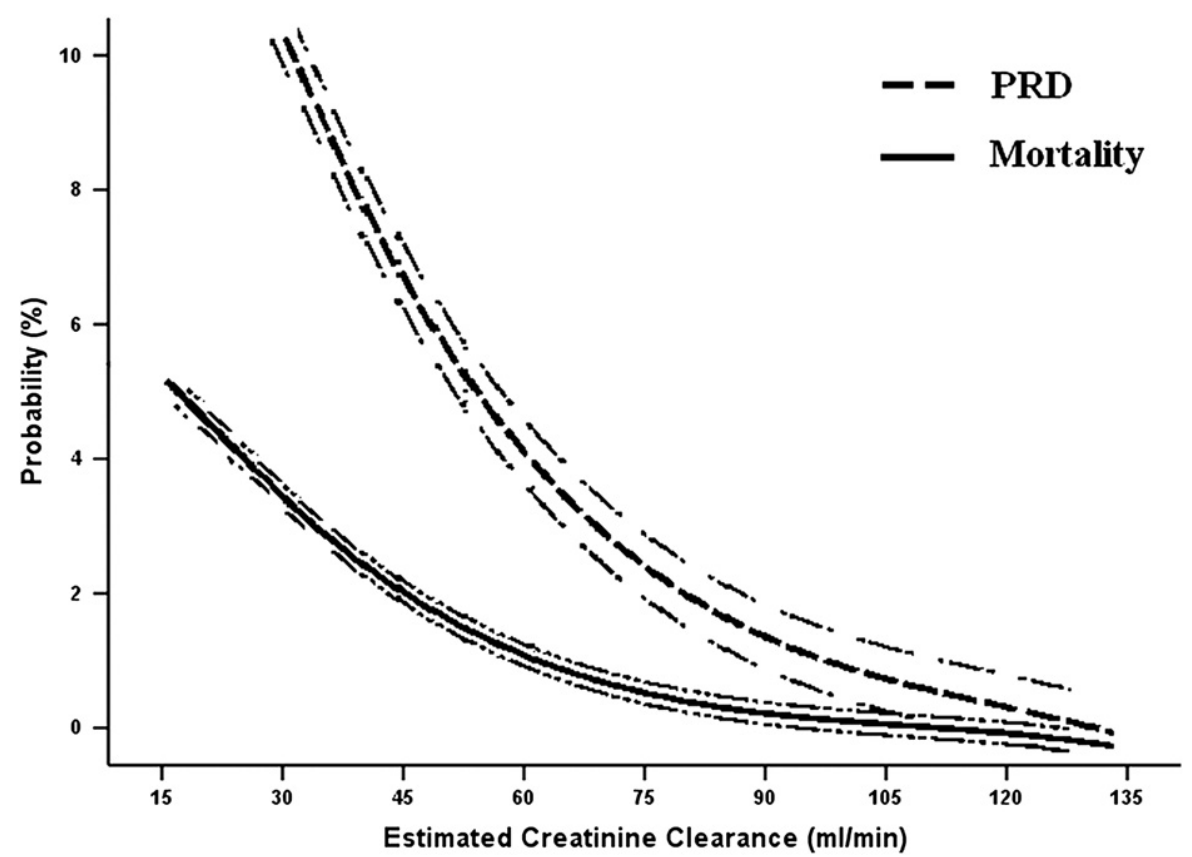

FIGURE 2. Probability of death and postoperative renal dysfunction (PRD) according to preoperative estimated creatinine clearance.

a nonselective population of patient with either ischemic or valvular heart disease, which could be a significant bias in retrospective studies. Furthermore, the aim of these studies was to investigate the accuracy of $\mathrm{eCrCl}$ in predicting outcomes in several categories of risk (normal, mild, moderate, and severe renal dysfunction), including patients with high $\mathrm{SCr}$ creatinine levels. The risk associated with ORD was investigated in a rather limited sample size. Our study was based on a large homogenous group of patients with normal $\mathrm{SCr}$ levels undergoing isolated $\mathrm{CABG}$, confirming the greater sensitivity of $\mathrm{eCrCl}$ in predicting renal dysfunction, and adverse postoperative outcomes.

Among 9159 patients with normal $\mathrm{SCr}$ levels undergoing CABG, approximately $40 \%$ had an $\mathrm{eCrCl}<60 \mathrm{~mL} / \mathrm{min}$, suggestive of ORD. This differs from previous reports that found an incidence of ORD ranging from $6 \%$ to $28 \%{ }^{5,11,23}$ A possible explanation could be the different definition of normal range for $\mathrm{SCr}$ level. We defined $\mathrm{SCr}$ levels normal range between 30 and $130 \mu \mathrm{mol}(0.34-1.47$ $\mathrm{mg} / \mathrm{dL}$ ) and these limits represent the 97.5 percentile of the distribution of SCr levels in healthy male and female volunteers. ${ }^{8}$ In the other studies, the normal range for $\mathrm{SCr}$ was defined as $<100 \mu \mathrm{mol} / \mathrm{L}(1.1 \mathrm{mg} / \mathrm{dL}))^{5,11,23}$

The association between ORD and adverse outcomes in patients after CABG may have several explanations. In our study, patients in the ORD group had a higher prevalence of hypertension, diabetes, recent MI, left ventricular dysfunction, extracardiac arteriopaty, and chronic obstructive pulmonary disease, which are well-known cardiovascular risk factors for adverse events in CABG. The presence of nontraditional risk factors in renal dysfunction, such as ane- mia, abnormal calcium/phosphate metabolism, extracellular fluid volume overload, electrolyte imbalance, oxidative stress, inflammation, condition promoting coagulation, and the effects of toxic metabolitis might break up a delicate homeostasis leading to increased risk of acute renal failure and atrial fibrillation, which are strongly associated with mortality. ${ }^{14,24,25}$ These hypotheses raise the question of whether ORD is a marker or a risk factor for worse outcomes after CABG. However, in our study, we demonstrated that ORD remained a predictor of mortality and morbidity after multivariable analysis adjusting for baseline characteristics and propensity score. Furthermore, we found that the $\mathrm{eCrCl}$ formula was very sensitive in identifying and unmasking a consistent group of patients considered "normal" from a renal point of view.

\section{Limitations}

This study has several limitations. It is based on the retrospective analysis of our large institutional observational prospectively collected database, and we are unable to account for the influence of any residual unmeasured factors that could affect the adverse outcomes. Furthermore, we do not have the specific details on the intraoperative and postoperative management of these patients.

Mortality in coronary artery bypass grafting is a very infrequent event, and our data reflect this trend. In our study, the overall mortality in patients with normal creatinine levels was $1 \%$, but double in patients with ORD. We strongly believe that this association is not only statistically significant but also clinically important. 
The Cockcroft-Gault equation was developed to estimate $\mathrm{CrCl}$ rather than GFR; it may overestimate renal function, especially in the elderly and obese patients as compared with 24 hours urine collection samples. Finally, we do not have information regarding the role of nephropathy induced by contrast medium administered before serum creatinine was measured.

\section{CONCLUSIONS}

Our study shows that ORD, defined as normal creatinine level with impaired renal function is associated with increased mortality and postoperative morbidity in patients undergoing CABG. An accurate assessment of renal function by estimation of creatinine clearance, in addition to serum creatinine might identify higher risk patients and provide a better risk stratification that can help optimize therapeutic strategies in these patients.

This study was supported by The British Heart Foundation, the Garfield Weston Trust, and the NIHR Bristol Biomedical Research Unit in Cardiovascular Medicine. We would like to acknowledge all the medical and nursing staff who has contributed to the data collection.

\section{References}

1. Roques F, Nashef SAM, Micheal P, Gauducheau E, de Vincentiis C, Baudet E, et al. Risk factors and outcome in European cardiac surgery: analysis of the EuroSCORE multinational database of 19030 patients. Eur J Cardiothorac Surg. 1999; 15:816-23.

2. Lok CE, Austin PC, Wang H, Tu JV. Impact of renal insufficiency on short and long term outcomes after cardiac surgery. Am Heart J. 2004;148:430-8.

3. Devbhandari MP, Duncan AJ, Grayson AD, Fabri BM, Keenan DJM, Bridgewater B, et al., on the behalf of the North West quality improvement programme in cardiac interventions. Effect of risk-adjusted, non dialysis-dependent renal dysfunction on mortality and morbidity following coronary artery bypass surgery: a multicenter study. Eur J Cardiothorac Surg. 2006;29:964-70.

4. Zakeri R, Freemantle N, Barnett V, Lipkin GW, Bonser RS, Graham TR, et al. Relation between mild renal dysfunction and outcomes after coronary artery bypass grafting. Circulation. 2005;I12:270-5.

5. Wang F, Dupuis JY, Nathan H, Williams K. An analysis of the association between preoperative renal dysfunction and outcome in cardiac surgery. Estimated creatinine clearance or plasma creatinine level as measures of renal function. Chest. 2003;124:1852-62.

6. Weerasinghe A, Hornick P, Smith P, Taylor K, Ratnatunga C. Coronary artery bypass grafting in non-dialysis dependent mild to moderate renal dysfunction. J Thorac Cardiovasc Surg. 2001;121:1083-9.

7. Stevens LA, Cresh J, Greene T, Levey AS. Assessing Kidney function-measured and estimated glomerular filtration rate. $N$ Engl J Med. 2006;354:2473-83.
8. Duncan L, Heathcote J, Djurdjev O, Levin A. Screening for renal disease using serum creatinine: who are we missing? Nephrol Dial Trasplant. 2001;16:1042.

9. Holzmann MJ, Ahnve S, Hammar N, Jörgensen L, Klerdal K, Pehrsson K, et al. Creatinine clearance and risk of early mortality in patients undergoing coronary artery bypass grafting. J Thor Cardiovasc Surg. 2005;130:746-52.

10. Noyez L, Plesiewicz I, Verheugt FWA. Estimated creatinine clearance instead of plasma creatinine level as prognostic test for postoperative renal function in patients undergoing coronary artery bypass surgery. Eur J Cardiothorac Surg. 2006;29:461-5

11. Wijeysundera DN, Karkouti K, Beattie WS, Rao V, Ivanov J. Improving the identification of patients at risk of postoperative renal failure after cardiac surgery. Anesthesiology. 2006;104:65-72.

12. Cooper WA, O'Brien SM, Thourani VH, Guyton RA, Bridges CR, Szczech LA, et al. Impact of renal dysfunction on outcomes of coronary artery bypass surgery. Results from the Society of Thoracic surgeons National Adult database. Circulation. 2006;113:1063-70.

13. National Kidney Foundation. Kidney Disease Outcome Quality Initiative (K/ DOQI) clinical practice guidelines for chronic kidney disease: evaluation, classification and stratification. Am J Kidney Dis. 2002;39:S1-266.

14. Sarnak MJ, Levey AS, Choolwerth AC, Coresh J, Culleton B, Hamm LL, et al. Kidney disease as a risk factor for development of cardiovascular disease. A statement from the American Heart association councils on Kidney in cardiovascular disease, high blood pressure research, clinical cardiology, and epidemiology and prevention. Circulation. 2003;108:2154-69.

15. Astor BC, Hallan SI, Miller ER III, Yeung E, Coresh J. Glomerular filtration rate, albuminuria, and risk of cardiovascular and all-cause mortality in the US population. Am J Epidemiol. 2008;167:1226-34.

16. Cockcroft DW, Gault MH. Prediction of creatinine clearance from serum creatinine. Nephron. 1976;16:31-41.

17. Ascione R, Caputo M, Calori G, Lloyd C, Underwood M, Angelini GD. Predictors of atrial fibrillation after conventional and beating heart coronary surgery. A prospective randomised study. Circulation. 2000;102:1530-5.

18. Watters M, Ascione R, Ryder I, Ciulli F, Pitsis AA, Angelini GD. Hemodynamic changes during beating heart coronary surgery with the "Bristol Technique. Eur J Cardiothorac Surg. 2001;19:34-40.

19. Blackstone EH. Comparing apples and oranges J. Thorac Cardiovasc Surg. 2002; 123:8-15.

20. Parsonnet V, Dean D, Bernstein AD. A method of uniform stratification of risk for evaluating the results of surgery in acquired adult heart disease. Circulation. 1989;79:3-12.

21. Shahian DM, O'Brien SM, Filardo G, Ferraris VA, Haan CK, Rich JB, et al. The Society of Thoracic Surgeons 2008 Cardiac Surgery Risk Models: Part 1- Coronary Artery Bypass Grafting Surgery. Ann Thorac Surg. 2009;88: S2-22.

22. Van Straten AHM, Soliman Hamad MA, van Zundert AAJ, Martens EJ, Schönerger JPAM, de Wolf AM. Preoperative renal function as a predictor of survival after coronary artery bypass grafting: comparison with a matched general population. J Thoracic Cardiovasc Surg. 2009;138:971-6.

23. Najafi M, Goodarzynejad H, Karimi A, Ghiasi A, Soltaninia H, Marzban M, et al. Is preoperative serum creatinine a reliable indicator of outcome in patients undergoing coronary artery bypass surgery? J Thor Cardiovasc Surg. 2009;137:304-8.

24. Villareal RP, Hariharan R, Liu BC, Kar B, Lee V, Elayda M, et al. Postoperative atrial fibrillation and mortality after coronary artery bypass surgery. J Am Coll Cardiol. 2004;43:742-8.

25. Rosner MH, Okusa MD. Acute kidney injury associated with cardiac surgery. Clin J Am Soc Nephrol. 2006;1:19-32. 